\title{
Optimal timing of surgical antimicrobial prophylaxis in laparoscopic surgery: a before-after study
}

\author{
Akane Takamatsu', Yasuaki Tagashira ${ }^{1}$, Kaori Ishii ${ }^{2}$, Yasuhiro Morita ${ }^{3}$, Yasuharu Tokuda ${ }^{4}$ and Hitoshi Honda ${ }^{*}$
}

\begin{abstract}
Background: The optimal timing of preoperative surgical antimicrobial prophylaxis (SAP) remains uncertain. This study aimed to evaluate the impact of changing the timing of SAP on the incidence of surgical site infection (SSI) in laparoscopic surgery.

Methods: We performed a before-after study from August 2014 through June 2017 to assess the impact of changes in the timing of SAP on the incidence of SSI at a 790-bed tertiary care center in Japan. The intervention was the administration of SAP immediately after the study patients entered the operating room for laparoscopic surgery.

Results: In total, 1397 patients who met the inclusion criteria were analyzed. After the intervention, the median time between the time of SAP completion and the time of surgical incision changed from 8 min to 26 min $(p<0.001)$, and the number of cases without SAP completion prior to surgical incision decreased (16.8\% vs. 1.8\%; $p<0.001$ ). However, changes in the overall incidence of SSI did not significantly differ between the pre-intervention and the intervention groups (13.8\% vs. $13.2 \% ; p=0.80$ ).

Conclusions: Although the timing of preoperative SAP improved, the intervention did not have a significant impact on reducing the incidence of SSI in the current study. Besides preoperative SAP, multidisciplinary approaches should be incorporated into projects aimed at comprehensively improving surgical quality to reduce SSI.
\end{abstract}

Keywords: Surgical antimicrobial prophylaxis, Laparoscopic surgery, Surgical site infection

\section{Introduction}

Surgical site infection (SSI) is one of the most common healthcare-associated infections in the acute care setting [1]. The incidence of SSI varies sociogeographically and by patient-related factors, such as co-morbidities and surgery-related factors, including type of surgery $[1,2]$.

Surgical antimicrobial prophylaxis (SAP) is one of the most important modifiable factors for reducing SSI incidence. Administering SAP within 120 min before surgery decreased the risk of SSI, and the rate of SSI increased with each hour after the incision until SAP was administered [3]. Guidelines for preventing SSI were published by the World Health Organization (WHO) in

\footnotetext{
*Correspondence: hhhhonda@gmail.com

${ }^{1}$ Division of Infectious Diseases, Tokyo Metropolitan Tama Medical Center,

2-8-29 Musashidai, Fuchu, Tokyo, Japan

Full list of author information is available at the end of the article
}

2016 and by the Centers for Disease Control and Prevention (CDC) in 2017 [1, 4]. Although these guidelines recommend preoperative SAP within one hour of surgical incision, the optimal timing of SAP during this period (e.g., 0-30 min versus 30-60 min before incision) remains unclear.

In Japan, a number of studies on the incidence of SSI and risk factors associated with SSI in selected surgical procedures were done using a Japanese national database $[5,6]$. The cumulative incidence of SSI in gastric and colorectal surgery ranged from 8.8 to $17.8 \%[5,6]$. Moreover, cases without complete preoperative SAP prior to the first incision in laparoscopic surgery were occasionally observed at the study institution. The infection control team at the study institution administered preoperative SAP earlier to ensure adequate time between the completion of SAP and the first skin incision as a

(c) The Author(s). 2018 Open Access This article is distributed under the terms of the Creative Commons Attribution 4.0 International License (http://creativecommons.org/licenses/by/4.0/), which permits unrestricted use, distribution, and 
part of a standard quality improvement initiative. The aim of this study was to evaluate the impact of changing the timing of preoperative SAP on SSI incidence in laparoscopic surgery.

\section{Methods}

\section{Study design and setting}

This before-after study was conducted from August 2014 to June 2017 at Tokyo Metropolitan Tama Medical Center, a 790-bed tertiary care center in Tokyo. Approximately 7000 patients annually undergo surgery at the study institution. The patients' informed consent was obtained before surgery. The institutional review board at Tokyo Metropolitan Tama Medical Center approved this study.

\section{Participants}

Patients over age 16 years who underwent any form of laparoscopic surgery including cholecystectomies, colectomies, gastrectomies, appendectomies, and proctectomies at the study institution were included for analysis. Patients who underwent laparoscopic surgery without follow-up information 30 days after the procedure were excluded.

\section{Intervention}

During the pre-intervention period (August 2014 - June 2016), the timing of preoperative SAP differed for each operation. In July 2016, the practice of administering SAP immediately after patients enter the operating room was implemented. Once patients were transferred into the operating room, intravenous SAP was immediately administered by anesthesiologists. If vancomycin or fluoroquinolone was used for SAP, administration of the agent was begun in the hospital ward before the patient was transferred to the operating room because both of these agents require a longer period of administration. Besides the intervention noted above, there were no concurrent changes in perioperative management, including the type and dosage of antimicrobials for SAP during the study period. The recommended SAP at the study institution is described in Appendix 1.

\section{Data collection}

Clinical data were extracted from the electronic medical records. We also determined the type of laparoscopic surgery done, time of administration and completion of preoperative SAP, the American Society of Anesthesiologists (ASA) score, wound class, demographic characteristics, and underlying illnesses. Because SAP was administered intravenously over 15-30 min, we collected the data on the time of SAP completion and surgical incision. The primary outcome was the incidence of SSI as defined by the CDC criteria [7, 8]. Nurses and physicians in the department of infection control determined whether SSI developed in the study subjects. Patients

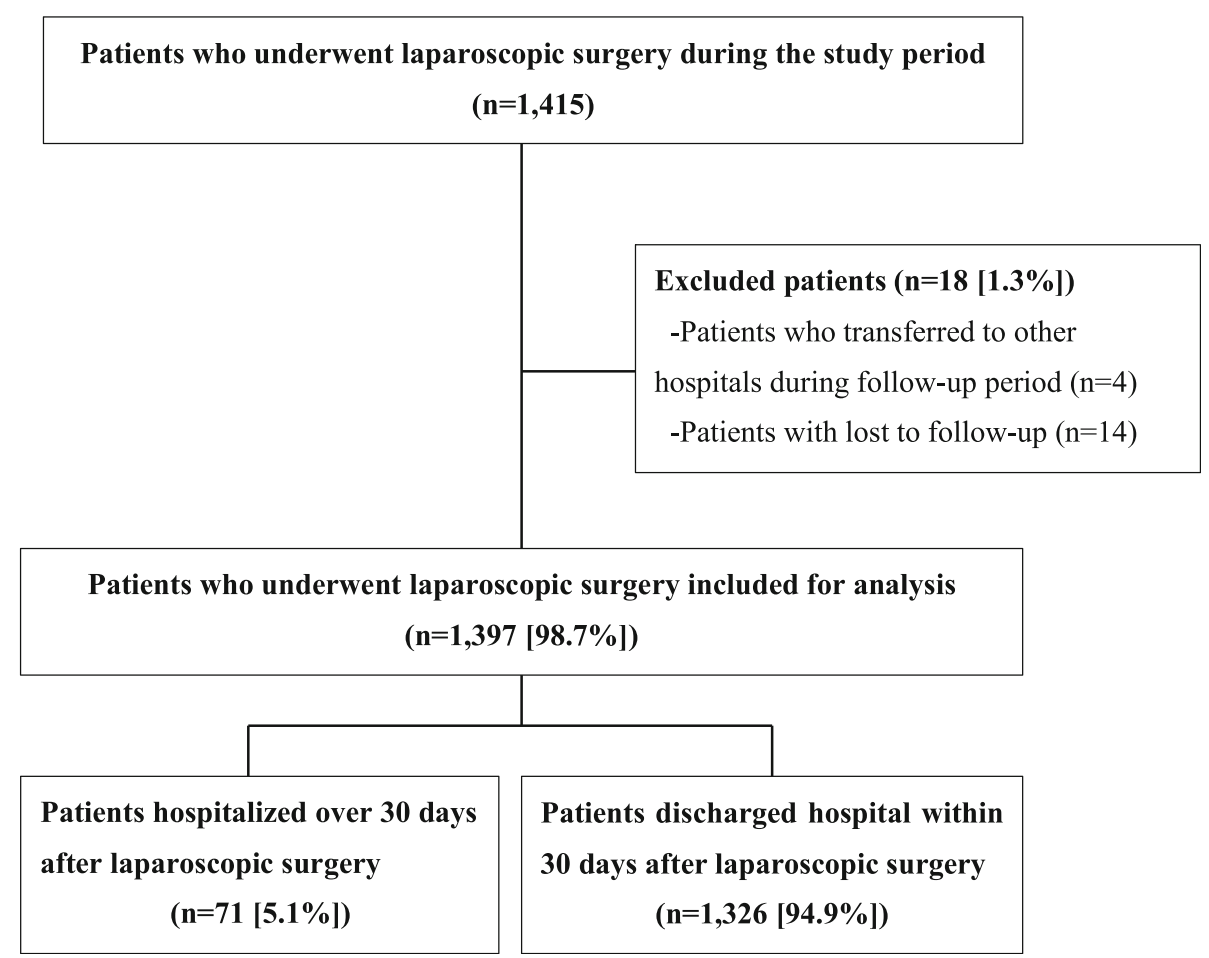

Fig. 1 Description of the study population 
who were discharged within the follow-up period were observed at follow-up visits as outpatients. The primary interest of this study was to examine if changing the timing of preoperative SAP affected the incidence of SSI.

\section{Statistical analysis}

We compared the incidence of SSI between the pre-intervention and intervention periods using the chi-square test. We also compared other, selected factors between the study periods. The changes in SSI incidence due to the intervention were also evaluated by segmented regression analysis of interrupted time series (ITS) data. For the sensitivity analysis, factors associated with SSI in the study period were also investigated. The usual time point of SAP (i.e., 31-60 min prior to surgical incision as a reference, in comparison with $0-30 \mathrm{~min}$

Table 1 Baseline characteristics of patients who underwent laparoscopic surgery in the study period $(n=1397)$

\begin{tabular}{|c|c|c|c|}
\hline & $\begin{array}{l}\text { Pre-intervention } \\
(n=942)\end{array}$ & $\begin{array}{l}\text { Intervention } \\
(n=455)\end{array}$ & $P$ value \\
\hline Age, median, (IQR) years & $66(52-75)$ & $68(55-76)$ & 0.04 \\
\hline Male gender, n (\%) & $431(56.4)$ & $260(57.1)$ & 0.79 \\
\hline \multicolumn{4}{|l|}{ Co-morbidities, n (\%) } \\
\hline Diabetes mellitus & $129(13.7)$ & $63(13.8)$ & 0.94 \\
\hline Chronic lung diseases & $42(4.5)$ & $27(5.9)$ & 0.23 \\
\hline Cardiovascular diseases & $37(3.9)$ & $32(7.0)$ & 0.01 \\
\hline Hypertension & $333(35.4)$ & $180(39.6)$ & 0.14 \\
\hline Dyslipidemia & $158(16.8)$ & $73(16.0)$ & 0.76 \\
\hline Current smoker, n (\%) & $446(47.4)$ & $224(49.2)$ & 0.51 \\
\hline \multicolumn{4}{|l|}{ ASA score, n (\%) } \\
\hline 1 no disturbance & $207(22.0)$ & $72(15.8)$ & Ref. \\
\hline 2 mild disturbance & $654(69.4)$ & $344(75.6)$ & 0.01 \\
\hline 3 severe disturbance & $79(8.4)$ & $37(8.1)$ & 0.22 \\
\hline 4 life-threatening & $2(0.2)$ & $2(0.4)$ & 0.30 \\
\hline \multicolumn{4}{|l|}{ Wound class, n (\%) } \\
\hline 2 clean-contaminated & $936(99.4)$ & $454(99.8)$ & 0.44 \\
\hline 3 contaminated & $6(0.6)$ & $1(0.2)$ & 0.44 \\
\hline Emergent operation, n (\%) & $152(16.1)$ & $70(15.4)$ & 0.72 \\
\hline \multicolumn{4}{|l|}{ Type of surgery, n (\%) } \\
\hline Gastrectomy & $242(25.7)$ & $129(28.4)$ & 0.29 \\
\hline Cholecystectomy & $213(22.6)$ & $94(20.7)$ & 0.41 \\
\hline Appendectomy & $125(13.3)$ & $32(7.0)$ & 0.001 \\
\hline Colectomy & $130(13.8)$ & $70(15.4)$ & 0.43 \\
\hline Proctectomy & $231(24.5)$ & $130(28.6)$ & 0.11 \\
\hline $\begin{array}{l}\text { Cholecystectomy and } \\
\text { appendectomy }\end{array}$ & $1(0.1)$ & $0(0)$ & N/A \\
\hline $\begin{array}{l}\text { Operation time, median, } \\
\text { (IQR) min }\end{array}$ & $213(133-286)$ & $222(145-322)$ & 0.003 \\
\hline
\end{tabular}

Abbreviations: IQR interquartile range, ASA American Society of Anesthesiologists, $N / A$ not applicable and $>60 \mathrm{~min}$ ) was used as a variable in the final model. Categorical variables were compared using Fisher's exact test or the chi-square test as appropriate. Continuous variables were compared using the Mann-Whitney $U$ test. All the analyses were performed using Stata version 15 (StataCorp, College Station, TX, USA) and SPSS version 21 (IBM, Armonk, NY, USA).

\section{Results}

Of the 1415 patients who underwent laparoscopic surgery during the study period, 1397 patients met the inclusion criteria (Fig. 1). Table 1 shows a summary of the patients' baseline characteristics. In the intervention group, the median age was higher (68 years old vs. 66 years old; $p=0.04$ ), and the proportion of selected comorbidities, such as cardiovascular diseases, was greater ( $7 \%$ vs. $3.9 \% ; p=0.01$ ). Table 2 shows the changes in outcomes after implementing the intervention. The median interval between the time of completion of preoperative SAP and the time of surgical incision changed from $8 \mathrm{~min}$ to $26 \mathrm{~min}(p<0.001)$, and the number of cases without a complete preoperative SAP prior to surgical incision decreased $(16.8 \%$ vs. $1.8 \% ; p<0.001)$. However, the incidence of SSI did not significantly change between the pre-intervention and the intervention groups $(13.8 \%$ vs. $13.2 \%$; $p=0.80)$. The ITS model shown in Fig. 2 also revealed no statistically significant changes in SSI incidence after the intervention (intercept: $P=0.86$; trend: $P=0.83$ ). The model of factors associated with SSI development and the result of

Table 2 Changes in outcomes after the intervention of SAP

\begin{tabular}{llll}
\hline & $\begin{array}{l}\text { Pre-intervention } \\
(n=942)\end{array}$ & $\begin{array}{l}\text { Intervention } \\
(n=455)\end{array}$ & $P$ value \\
\hline SAP, n (\%) & $940(99.8)$ & $455(100)$ & \\
$\begin{array}{l}\text { SAP drip infusion time, } \\
\text { median, (IQR) min }\end{array}$ & $16(13-20)$ & $23(17-30)$ & $<0.001$ \\
$\begin{array}{l}\text { Time from SAP completion } \\
\text { to surgical incision, median, } \\
\text { (IQR) min }\end{array}$ & $8(2-16)$ & $26(15-35)$ & $<0.001$ \\
$\begin{array}{l}\text { Time windows, n (\%) } \\
>120 \text { min }\end{array}$ & $13(1.4)$ & $3(0.7)$ & 0.18 \\
$\quad 11(1.2)$ & $5(1.1)$ & 0.57 \\
61-120 min & $56(5.9)$ & $161(35.4)$ & $<0.001$ \\
0-30 min & $702(74.5)$ & $278(61.1)$ & $<0.001$ \\
$<0$ min & $158(16.8)$ & $8(1.8)$ & $<0.001$ \\
SSI, n (\%) & $130(13.8)$ & $60(13.2)$ & 0.80 \\
Type of SSI, n (\%) & & & \\
Superficial SSI & $78(8.3)$ & $35(7.7)$ & 0.71 \\
Deep SSI & $0(0)$ & $4(0.9)$ & N/A \\
Organ-space SSI & $52(5.5)$ & $21(4.6)$ & 0.48 \\
\hline
\end{tabular}

Abbreviations: SAP surgical antimicrobial prophylaxis, IQR interquartile range, SSI surgical site infection, N/A not applicable 


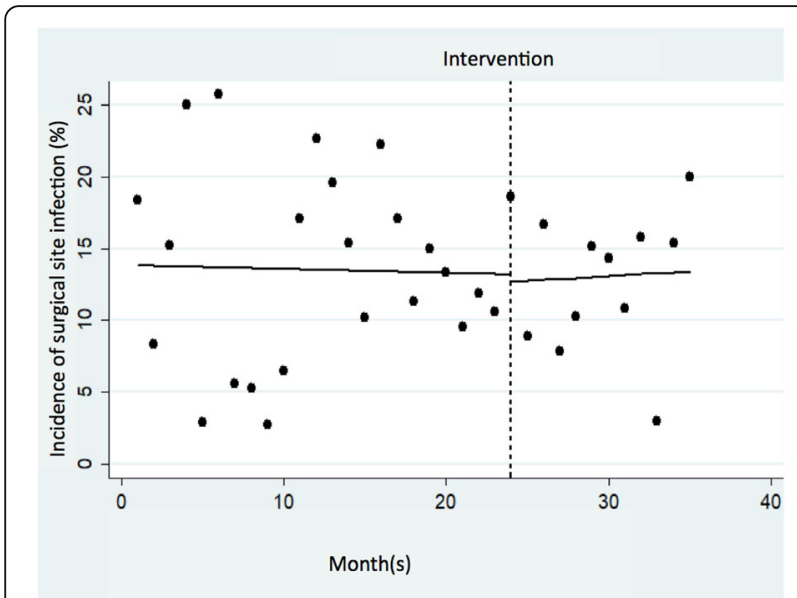

Fig. 2 Interrupted time series analysis for assessing the impact of surgical antimicrobial prophylaxis intervention on the incidence of surgical site infection

sensitivity analysis is shown in Appendix 2 (univariate analysis) and Table 3 (multivariate analysis), respectively. Overall, a trend towards older age and longer duration of surgery was observed in patients with SSI compared with those without SSI. The results of subgroup analysis for surgery type and SSI type are shown in Appendix 3. For all types of surgery, the number of cases without complete preoperative SAP prior to surgical incision decreased.

\section{Discussion}

In this study, we were able to prolong the interval between the completion of preoperative SAP and the first incision in laparoscopic surgery and to decrease the number of cases without complete preoperative SAP prior to surgical incision. The intervention successfully improved the quality of perioperative care in terms of SAP and likely increased awareness of the importance of SAP among health care workers. However, the intervention did not lead to a decrease in SSI incidence.

A number of studies have examined the optimal timing of preoperative SAP, with some studies showing that administration within $30 \mathrm{~min}$ prior to incision decreased the risk of postoperative infection $[9,10]$. Other studies have reported that administration 30 to 60 min prior to incision was most effective in preventing SSI [11]. A recent systematic review demonstrated that the risk of SSI increased when preoperative SAP was administered $120 \mathrm{~min}$ before or after the first incision [12] while the WHO recommended that administration should be closer to the incision time $(<60 \mathrm{~min})$ for antimicrobials with a short half-life, such as cephalosporins and penicillins [1]. At the moment, there are insufficient data to establish a more precise window $[2,13]$, and the present study was also unable to demonstrate the optimal timing for preoperative SAP.

A few previous studies showed that the risk of SSI increased when SAP was administered after incision $[5,12]$. However, in the current study SSI incidence did not improve in the intervention period despite a decrease in the number of cases without a complete preoperative SAP prior surgical incision. Although the reasons for this result are unclear, several factors may have played a role. For instance, patients' age in the intervention period was slightly higher than in the pre-intervention period. Previous studies showed an association between aging and increased

Table 3 Univariate and multivariate analyses for potential risk factors for SSI

\begin{tabular}{|c|c|c|c|c|}
\hline & $\begin{array}{l}\text { Univariate analyses, } \\
\text { OR }(95 \% \mathrm{Cl})\end{array}$ & $P$ value & $\begin{array}{l}\text { Multivariate analyses, } \\
\text { OR ( } 95 \% \text { CI) }\end{array}$ & $P$ value \\
\hline Age $\geq 65$ & $1.44(1.05-1.98)$ & 0.02 & & \\
\hline Male gender & $0.82(0.60-1.12)$ & 0.21 & & \\
\hline Diabetes mellitus & $0.90(0.59-1.40)$ & 0.65 & & \\
\hline Current smoker & $1.61(1.12-2.20)$ & 0.003 & $1.66(1.14-2.40)$ & 0.01 \\
\hline ASA score $\geq 2$ & $1.44(0.95-2.19)$ & 0.09 & & \\
\hline Wound class 3 contaminated & $2.57(0.50-13.36)$ & 0.26 & & \\
\hline Emergent surgery & $0.63(0.39-1.01)$ & 0.06 & & \\
\hline Operation time $\geq 180 \mathrm{~min}$ & $2.58(1.79-3.71)$ & $<0.001$ & $2.35(1.56-3.54)$ & $<0.001$ \\
\hline \multicolumn{5}{|l|}{ Time windows, } \\
\hline $31-60 \mathrm{~min}$ & & Ref. & & Ref. \\
\hline$<0 \min$ & $0.67(0.38-1.17)$ & 0.16 & $0.78(0.41-1.46)$ & 0.43 \\
\hline $0-30 \mathrm{~min}$ & $0.58(0.39-0.85)$ & 0.01 & $0.65(0.41-1.00)$ & 0.052 \\
\hline$>60 \min$ & $0.72(0.26-1.97)$ & 0.52 & $1.14(0.38-3.42)$ & 0.81 \\
\hline Intervention status, "yes" & $0.96(0.69-1.33)$ & 0.80 & $0.79(0.54-1.15)$ & 0.22 \\
\hline
\end{tabular}


risk of SSI $[2,14,15]$. Japan is one of the countries with an aging demographic [16]. Moreover, as seen in Table 2, the median duration of surgery in the intervention period was longer than in the pre-intervention period, an important risk factor for developing SSI [17]. Prolonged operative time in the intervention period might be explained by the patients' age, which in turn was associated with a higher rate of comorbidities such as cardiovascular disease and a higher ASA score. Although SAP is one of the most important modifiable factors for reducing SSI, other, unmodifiable factors, including patient factors, might significantly contribute to the development SSI.

There are some limitations to our study. It is unclear whether the results would last beyond the brief, post-intervention period. Although patients' baseline characteristics in both study periods were compared, the number of collected variables was limited, and potentially predisposing factors such as body mass index, steroid use, and nutritional status, which may have differed between the study periods, were not measured [2]. We also did not track information on the dosage of antimicrobials used in SAP or in additional antimicrobial administration for the longer operations. Lastly, as mentioned above, other modifiable measures (e.g. adequate skin preparation solutions, patient warming, and glycemic control) might have played an important role in preventing SSI.

\section{Conclusions}

Although preoperative SAP is important, the timing of preoperative SAP within the 60-min window may be a minor detail for laparoscopic surgery. Moreover, other modifiable measures should be incorporated into comprehensive surgical quality improvement initiatives to reduce SSI.

\section{Appendix}

Appendix 1 Recommended preoperative surgical antimicrobial prophylaxis at the study institution

\begin{tabular}{llll}
\hline $\begin{array}{l}\text { Type of } \\
\text { procedure }\end{array}$ & Agents & Dose & $\begin{array}{l}\text { Redosing } \\
\text { interval, hour }\end{array}$ \\
\hline Gastrectomy & cefazolin & $1-2 \mathrm{~g}$ & $3-4$ \\
Cholecystectomy & cefazolin & $1-2 \mathrm{~g}$ & $3-4$ \\
& ampicillin/sulbactam & $1.5-3 \mathrm{~g}$ & $2-3$ \\
Appendectomy & cefazolin + & $1-2 \mathrm{~g}+500 \mathrm{mg}$ & $3-4+8$ \\
& metronidazole & $1-2 \mathrm{~g}$ & $2-3$ \\
& cefmetazole & $1.5-3 \mathrm{~g}$ & $2-3$ \\
ampicillin/sulbactam & & \\
colorectal & cefazolin + & $1-2 \mathrm{~g}+$ & $3-4+8$ \\
& metronidazole & $500 \mathrm{mg}$ & $2-3$ \\
& cefmetazole & $1-2 \mathrm{~g}$ & $2-3$ \\
& ampicillin/sulbactam & $1.5-3 \mathrm{~g}$ & \\
\hline
\end{tabular}

NOTE. For patients with $\beta$-lactam allergy and renal failure, infectious disease consultation is recommended
Appendix 2 Univariate analysis of factors associated with development of SSI

\begin{tabular}{|c|c|c|c|}
\hline Variables & $\begin{array}{l}\text { No SSI } \\
n=1207\end{array}$ & $\begin{array}{l}\text { SSI } \\
n=190\end{array}$ & $P$ value \\
\hline Age, median, (IQR) years & $66(52-75)$ & $70(60-77)$ & 0.001 \\
\hline$<65, \mathrm{n}(\%)$ & $554(45.9)$ & $71(37.4)$ & 0.028 \\
\hline$\geq 65, \mathrm{n}(\%)$ & $653(54.1)$ & $119(62.6)$ & \\
\hline Male gender, n (\%) & $532(44.1)$ & $74(39.0)$ & 0.19 \\
\hline \multicolumn{4}{|l|}{ Co-morbidities, n (\%) } \\
\hline Diabetes mellitus & $164(13.6)$ & $28(14.7)$ & 0.67 \\
\hline Chronic lung diseases & $57(4.7)$ & $12(6.3)$ & 0.35 \\
\hline Cardiovascular diseases & $59(4.9)$ & $10(5.3)$ & 0.83 \\
\hline Hypertension & $442(36.6)$ & $71(37.4)$ & 0.84 \\
\hline Dyslipidemia & $198(16.4)$ & $33(17.4)$ & 0.74 \\
\hline Current smoker, n (\%) & $560(46.4)$ & $110(47.9)$ & 0.003 \\
\hline \multicolumn{4}{|l|}{ ASA score, n (\%) } \\
\hline 1 no disturbance & $250(20.7)$ & $29(15.3)$ & Ref. \\
\hline 2 mild disturbance & $854(70.8)$ & $144(75.8)$ & 0.08 \\
\hline 3 severe disturbance & $99(8.2)$ & $17(9.0)$ & 0.23 \\
\hline 4 life-threatening & $4(0.3)$ & $0(0)$ & N/A \\
\hline \multicolumn{4}{|l|}{ Wound class, n (\%) } \\
\hline 2 clean-contaminated & 1202 (99.6) & $188(99.0)$ & 0.25 \\
\hline 3 contaminated & $5(0.4)$ & $2(1.1)$ & 0.25 \\
\hline Emergent surgery, n (\%) & $200(16.6)$ & $22(11.6)$ & 0.080 \\
\hline \multicolumn{4}{|l|}{ Type of surgery, n (\%) } \\
\hline Cholecystectomy & $291(24.1)$ & $16(8.4)$ & Ref. \\
\hline Gastrectomy & $294(24.4)$ & $77(40.5)$ & $<0.001$ \\
\hline Appendectomy & $140(11.6)$ & $17(9.0)$ & 0.029 \\
\hline Colectomy & $175(14.5)$ & $25(13.2)$ & 0.004 \\
\hline Proctectomy & $306(25.4)$ & $55(29.0)$ & $<0.001$ \\
\hline $\begin{array}{l}\text { Cholecystectomy and } \\
\text { appendectomy }\end{array}$ & $1(0.1)$ & $0(0)$ & N/A \\
\hline $\begin{array}{l}\text { Operation time, median, } \\
\text { (IQR) min }\end{array}$ & $205(131-285)$ & $273(197-337)$ & $<0.001$ \\
\hline$<180, \mathrm{n}(\%)$ & $502(41.6)$ & $42(22.1)$ & \\
\hline$\geq 180, \mathrm{n}(\%)$ & $705(58.4)$ & $148(77.9)$ & $<0.001$ \\
\hline $\begin{array}{l}\text { SAP drip infusion time, } \\
\text { median, (IQR) min }\end{array}$ & $18(14-23)$ & $18(14-24)$ & 0.97 \\
\hline $\begin{array}{l}\text { Time from SAP completion } \\
\text { to surgical incision, median, } \\
\text { (IQR) min }\end{array}$ & $12(4-25)$ & $15(3-31)$ & 0.37 \\
\hline $31-60 \mathrm{~min}$ & $175(14.5)$ & $42(22.2)$ & Ref. \\
\hline$<0 \min$ & $143(11.9)$ & $23(12.2)$ & 0.16 \\
\hline $0-30 \mathrm{~min}$ & $861(71.4)$ & $119(63.0)$ & 0.005 \\
\hline$>60 \min$ & $26(2.2)$ & $6(3.2)$ & 0.52 \\
\hline Intervention status, "yes" & 395 (32.7) & 60 (31.6) & 0.75 \\
\hline
\end{tabular}

NOTE. SSI surgical site infection, IQR interquartile range, ASA American Society of Anesthesiologists, SAP surgical antimicrobial prophylaxis, N/A not applicable 
Appendix 3 Subgroup analysis of different types of SSI

\begin{tabular}{|c|c|c|c|c|c|}
\hline & No SSI & Superficial SSI & & $P$ value & \\
\hline & & & $\begin{array}{l}\text { space ssl } \\
(n=77)\end{array}$ & $\begin{array}{l}\text { No SSI vS } \\
\text { superficial SSI }\end{array}$ & $\begin{array}{l}\text { No SSI vs deep } \\
\text { and organ space SSI }\end{array}$ \\
\hline Age, median, (IQR) years & $66(52-75)$ & $67(53-76)$ & $72(64-78)$ & 0.49 & $<0.001$ \\
\hline$<65, \mathrm{n}(\%)$ & $554(45.9)$ & $50(44.3)$ & $21(27.3)$ & 0.74 & 0.018 \\
\hline$\geq 65, \mathrm{n}(\%)$ & $653(54.1)$ & $63(55.7)$ & $56(72.7)$ & & \\
\hline Male gender, n (\%) & $532(44.1)$ & $57(50.4)$ & $17(22.1)$ & 0.19 & $<0.001$ \\
\hline Co-morbidities, n (\%) & & & & & \\
\hline Diabetes mellitus & $164(13.6)$ & $13(11.5)$ & $15(19.5)$ & 0.53 & 0.15 \\
\hline Chronic lung diseases & $57(4.7)$ & $6(5.3)$ & $6(7.8)$ & 0.78 & 0.23 \\
\hline Cardiovascular diseases & $59(4.9)$ & $7(6.2)$ & $3(3.9)$ & 0.54 & 0.69 \\
\hline Hypertension & $442(36.6)$ & 38 (33.6) & $33(42.9)$ & 0.53 & 0.27 \\
\hline Dyslipidemia & $198(16.4)$ & $19(16.8)$ & $14(18.2)$ & 0.91 & 0.68 \\
\hline Current smoker, n (\%) & $560(46.4)$ & $58(51.3)$ & $52(67.5)$ & 0.32 & $<0.001$ \\
\hline ASA score, n (\%) & & & & & \\
\hline 1 (no disturbance) & $250(20.7)$ & $22(19.5)$ & $7(9.1)$ & Ref. & Ref. \\
\hline 2 (mild disturbance) & $854(70.8)$ & $82(72.6)$ & $62(80.5)$ & 0.73 & 0.02 \\
\hline 3 (severe disturbance) & $99(8.2)$ & $9(8.0)$ & $8(10.4)$ & 0.94 & 0.05 \\
\hline 4 (life-threatening) & $4(0.3)$ & $0(0)$ & $0(0)$ & N/A & N/A \\
\hline Wound class, n (\%) & & & & & \\
\hline 2 clean-contaminated & 1202 (99.6) & $112(99.1)$ & $76(98.7)$ & 0.48 & 0.27 \\
\hline 3 contaminated & $5(0.4)$ & $1(0.9)$ & $1(1.3)$ & 0.48 & 0.27 \\
\hline Emergent surgery, n (\%) & $200(16.6)$ & $16(14.2)$ & $6(7.8)$ & 0.51 & 0.04 \\
\hline Type of surgery, n (\%) & & & & & \\
\hline Cholecystectomy & $291(24.1)$ & $11(9.7)$ & $5(6.5)$ & Ref. & Ref. \\
\hline Gastrectomy & $294(24.4)$ & $28(24.8)$ & 49 (63.6) & 0.011 & $<0.001$ \\
\hline Appendectomy & $140(11.6)$ & $14(12.4)$ & $3(3.9)$ & 0.019 & 0.77 \\
\hline Colectomy & $175(14.5)$ & $16(14.2)$ & $9(11.7)$ & 0.028 & 0.05 \\
\hline Proctectomy & $306(25.4)$ & $44(38.9)$ & $11(14.3)$ & $<0.001$ & 0.18 \\
\hline Cholecystectomy and appendectomy & $1(0.1)$ & $0(0)$ & $0(0)$ & N/A & N/A \\
\hline Operation time, median, (IQR) min & $205(131-285)$ & $229(164-296)$ & $325(271-399)$ & 0.015 & $<0.001$ \\
\hline$<180, \mathrm{n}(\%)$ & $502(41.6)$ & $33(29.2)$ & $9(11.7)$ & 0.01 & $<0.001$ \\
\hline$\geq 180, \mathrm{n}(\%)$ & $705(58.4)$ & $80(70.8)$ & $68(88.3)$ & & \\
\hline SAP drip infusion time, median, (IQR) min & $18(14-23)$ & $18(14-25)$ & $17(13-22)$ & 0.52 & 0.46 \\
\hline $\begin{array}{l}\text { Time from SAP completion to surgical } \\
\text { incision, median, (IQR) min }\end{array}$ & $12(4-25)$ & $14(2-31)$ & $17(6-29)$ & 0.39 & 0.69 \\
\hline Time windows, n (\%) & & & & & \\
\hline $31-60 \mathrm{~min}$ & $175(14.5)$ & $24(21.2)$ & $18(23.4)$ & Ref. & Ref. \\
\hline$<0$ min & $143(11.9)$ & $18(15.9)$ & $5(6.5)$ & 0.80 & 0.04 \\
\hline $0-30 \mathrm{~min}$ & $861(71.4)$ & $65(57.5)$ & $54(70.1)$ & 0.02 & 0.08 \\
\hline$>60 \min$ & $26(2.2)$ & $6(5.3)$ & $0(0)$ & 0.30 & N/A \\
\hline Intervention status, "yes" & 395 (32.7) & 35 (31.0) & $25(32.5)$ & 0.70 & 0.83 \\
\hline
\end{tabular}

NOTE. SSI surgical site infection, IQR interquartile range, ASA American Society of Anesthesiologists, SAP surgical antimicrobial prophylaxis, N/A not applicable 


\section{Abbreviations}

ASA: American Society of Anesthesiologists; CDC: Center for Disease Control and Prevention; SAP: Surgical antimicrobial prophylaxis; SSI: Surgical site infection; WHO: World Health Organization

\section{Acknowledgements}

The authors thank James R. Valera for his assistance with editing the text.

\section{Funding}

None

\section{Availability of data and materials}

The datasets used and analyzed during the current study are available from the corresponding author on reasonable request.

\section{Authors' contributions}

AT analyzed the data and drafted and revised the manuscript. YT participated in designing the study, interpreted the data, and revised the manuscript. KI collected and analyzed the data. YM participated in designing the study. YT analyzed and interpreted the data. HH conceived and designed the study, interpreted the data, and revised the manuscript. All the authors read and approved the final manuscript.

\section{Ethics approval and consent to participate}

The institutional review board at Tokyo Metropolitan Tama Medical Center approved this study.

\section{Consent for publication}

Not applicable

\section{Competing interests}

The authors declare that they have no competing interests.

\section{Publisher's Note}

Springer Nature remains neutral with regard to jurisdictional claims in published maps and institutional affiliations.

\section{Author details}

${ }^{1}$ Division of Infectious Diseases, Tokyo Metropolitan Tama Medical Center, 2-8-29 Musashidai, Fuchu, Tokyo, Japan. '2Department of Infection Control, Tokyo Metropolitan Tama Medical Center, 2-8-29 Musashidai, Fuchu, Tokyo, Japan. ${ }^{3}$ Department of Surgery, Tokyo Metropolitan Tama Medical Center, 2-8-29 Musashidai, Fuchu, Tokyo, Japan. ${ }^{4}$ Muribushi Project for Teaching Hospitals, 3-42-8-901 Iso, Urasoe, Okinawa, Japan.

Received: 26 July 2018 Accepted: 17 October 2018

Published online: 31 October 2018

\section{References}

1. Allegranzi B, Bischoff $\mathrm{P}$, de Jonge S, Kubilay NZ, Zayed B, Gomes SM, et al, New WHO recommendations on preoperative measures for surgical site infection prevention: an evidence-based global perspective. Lancet Infect Dis. 2016;16:e276-87.

2. Bratzler DW, Dellinger EP, Olsen KM, Perl TM, Auwaerter PG, Bolon MK, et al. Clinical practice guidelines for antimicrobial prophylaxis in surgery. Surg Infect. 2013;14:73-156.

3. Classen DC, Evans RS, Pestotnik SL, Horn SD, Menlove RL, Burke JP. The timing of prophylactic administration of antibiotics and the risk of surgicalwound infection. N Engl J Med. 1992;326:281-6.

4. Berrios-Torres SI, Umscheid CA, Bratzler DW, Leas B, Stone EC, Kelz RR, et al. Centers for disease control and prevention guideline for the prevention of surgical site infection, 2017. JAMA Surg. 2017;152:784-91.

5. Morikane K, Honda H, Suzuki S. Factors associated with surgical site infection following gastric surgery in Japan. Infect Control Hosp Epidemiol. 2016:37:1167-72.

6. Morikane K, Honda H, Yamagishi T, Suzuki S, Aminaka M. Factors associated with surgical site infection in colorectal surgery: the Japan nosocomial infections surveillance. Infect Control Hosp Epidemiol. 2014;35:660-6.

7. Horan TC, Gaynes RP, Martone WJ, Jarvis WR. Emori TG. CDC definitions of nosocomial surgical site infections, 1992: a modification of CDC definitions of surgical wound infections. Infect Control Hosp Epidemiol. 1992;13:606-8.
8. Mangram AJ, Horan TC, Pearson ML, Silver LC, Jarvis WR. Guideline for prevention of surgical site infection, 1999. Hospital infection control practices advisory committee. Infect Control Hosp Epidemiol. 1999;20: 250-78.

9. Koch CG, Li L, Hixson E, Tang A, Gordon S, Longworth D, et al. Is it time to refine? An exploration and simulation of optimal antibiotic timing in general surgery. J Am Coll Surg. 2013;217:628-35.

10. Steinberg JP, Braun Bl, Hellinger WC, Kusek L, Bozikis MR, Bush AJ, et al. Timing of antimicrobial prophylaxis and the risk of surgical site infections: results from the trial to reduce antimicrobial prophylaxis errors. Ann Surg. 2009;250:10-6.

11. Weber WP, Marti WR, Zwahlen M, Misteli H, Rosenthal R, Reck S, et al. The timing of surgical antimicrobial prophylaxis. Ann Surg. 2008;247:918-26.

12. de Jonge SW, Gans SL, Atema JJ, Solomkin JS, Dellinger PE, Boermeester MA. Timing of preoperative antibiotic prophylaxis in 54,552 patients and the risk of surgical site infection: a systematic review and meta-analysis. Medicine (Baltimore). 2017;96:e6903.

13. Weber WP, Mujagic E, Zwahlen M, Bundi M, Hoffmann H, Soysal SD, et al. Timing of surgical antimicrobial prophylaxis: a phase 3 randomised controlled trial. Lancet Infect Dis. 2017;17:605-14.

14. Delgado-Rodriguez M, Gomez-Ortega A, Sillero-Arenas M, Llorca J. Epidemiology of surgical-site infections diagnosed after hospital discharge: a prospective cohort study. Infect Control Hosp Epidemiol. 2001;22:24-30.

15. Kaye KS, Schmit K, Pieper C, Sloane R, Caughlan KF, Sexton DJ, et al. The effect of increasing age on the risk of surgical site infection. J Infect Dis. 2005:191:1056-62

16. Statistic Hand book of Japan 2017. www.stat.go.jp/english/data/handbook/ pdf/2017all.pdf. Accessed 4 July 2018.

17. Kasatpibal N, Norgaard M, Sorensen HT, Schonheyder HC, Jamulitrat S, Chongsuvivatwong $\mathrm{V}$. Risk of surgical site infection and efficacy of antibiotic prophylaxis: a cohort study of appendectomy patients in Thailand. BMC Infect Dis. 2006;6:111.

\section{Ready to submit your research? Choose BMC and benefit from:}

- fast, convenient online submission

- thorough peer review by experienced researchers in your field

- rapid publication on acceptance

- support for research data, including large and complex data types

- gold Open Access which fosters wider collaboration and increased citations

- maximum visibility for your research: over $100 \mathrm{M}$ website views per year

At BMC, research is always in progress.

Learn more biomedcentral.com/submissions 